\title{
EDUCAÇÃO A DISTÂNCIA: AS (IM)POSSIBILIDADES DE UMA REDE CONFESSIONAL
}

\author{
ENGENHEIRO COELHO/SP JUNHO/2018 \\ Creriane Nunes Lima - UNASP - creriane.lima@ucb.org.br \\ Tipo: Relato de Experiência Inovadora (EI) \\ Categoria: Conteúdos e Habilidades \\ Setor Educacional: EDUCAÇÃO SUPERIOR
}

\begin{abstract}
RESUMO
O presente trabalho foi desenvolvido a partir da prática de gestão da pesquisadora como coordenadora do primeiro curso de Letras EaD, do UNASP, e como vice-coordenadora do curso de Letras presencial no UNASP-EC (Centro Universitário Adventista de São Paulo). Proponho-me aqui a analisar a aplicação da filosofia educacional da Rede Adventista no curso de Letras EaD, a partir de sua relação com o curso de Letras presencial. Ligado a pressupostos teóricos como os de White (2007 e 2008), Knight (2010 e 2012), Santaella (2009) entre outros, esperamos que este artigo venha contribuir para uma reflexão acerca da relação teoria-prática no contexto de formação humana, não apenas da Rede Adventista, mas de todos que, de alguma forma, se relacionam com o sistema confessional de ensino.

A partir dessa análise, propomos como resultado subsequente a esse relato de experiência inovadora, um projeto de pesquisa para uma futura investigação científica em formato de pesquisa qualitativa. $A$ relevância desta proposta se dá devido à necessidade de afirmação de identidade da Rede confessional Adventista frente às mudanças e novidades do ensino a distância em uma sociedade em constante processo de transformação.
\end{abstract}

Palavras-chave: educação a distância, educação confessional, licenciatura em letras

\section{AGRADECIMENTOS}

A ANDREA FILATRO, PELO INTERESSE, ORIENTAÇÃO E INCENTIVO. 


\section{Introdução}

Como docente, ao longo de 15 anos de experiência na modalidade presencial, perpassei pelos níveis da Educação Infantil, Ensino Fundamental, Médio e Superior, e agora, quando me considerava experiente e veterana, deparo-me com o desafio de coordenar o primeiro curso de licenciatura a distância de uma rede confessional, fato que me coloca no nível de iniciante e inexperiente, mais uma vez. O convite, prontamente recebido, para fazer parte do processo de implantação do curso de Letras a distância no UNASP-EaD veio em agosto de 2017.

Desde o início da carreira, uma das verdades muito claras que aprendi é a de que a mudança e a necessidade de ajustes e adequações são características inerentes ao magistério e à educação, em si. Enganam-se aqueles que acreditam que a sala de aula não tem mudado ou exigido mudanças do educador e do processo educativo ao longo dos séculos. Talvez não tenham tido eles mesmos o prazer de passar alguns anos lidando com gerações diferentes de alunos para perceber o quanto essa profissão é mutante, desafiadora e instável.

A proposta deste relato de experiência veio a calhar com minha vontade de, mais uma vez, entender e aplicar a filosofia adventista de educação à prática da sala de aula, desta vez na modalidade a distância. Assim, como coordenadora do curso de LetrasEaD e vice-coordenadora do curso de Letras presencial do UNASP, relato minha impressão e a primeira tentativa sistematizada de aplicar a filosofia adventista de ensino às aulas a distância do curso de licenciatura no Brasil.

\section{Objetivos}

O envolvimento nesse projeto tem por objetivo apresentar as ações práticas para concretizar a filosofia adventista de educação no contexto da educação a distância no curso de Letras EaD do UNASP, com base nas ações aplicadas ao curso presencial. No intuito de alcançar esse objetivo primário, seguem alguns objetivos específicos:

a. apresentar os pressupostos filosóficos confessionais da Rede Adventista de ensino;

b. apresentar as ações para efetivar a filosofia adventista de ensino nos cursos de Letras presencial e EaD do UNASP;

c. apresentar uma possibilidade de pesquisa futura para dimensionar a efetividade dessa filosofia na prática do ensino EaD. 


\section{Apresentação}

Para os que são da área da linguística, não há nada mais fascinante que refletir sobre as linguagens, os meios de comunicação e todas as formas que o homem usa essencialmente para entender o mundo e tentar ser entendido. No que diz respeito à educação, mudanças na forma de se expressar, de ler o mundo ao redor, de concepção de mundo, de criação de realidades e modos de aprendizagem nos provam que as tecnologias chegaram para transformar e revolucionar a linguagem e a comunicação humanas.

As últimas décadas desse momento tecnológico têm nos desafiado ao extremo quanto às possibilidades e formas de ensino/aprendizagem. De certa forma, a educação a distância chegou para abalar os fundamentos da educação tradicional. Mas, mesmos os mais críticos não esperavam que a tecnologia pudesse revolucionar tanto e causar tanto impacto na prática da educação e formação humana. Como não podia ser diferente, o sistema educacional uniu-se às boas oportunidades dessa era tecnológica e, apesar da certa lentidão, a educação a distância, através da popularização do acesso à internet, impacta nossa sociedade brasileira influenciando, não só a forma de ensinar e aprender, mas a própria forma cognitiva mental.

Santaella (2004) apresenta que o leitor imersivo/virtual, o leitor das hipermídias e da interatividade, possui "habilidades perceptivas, sensório-motoras e cognitivas distintas" (SANTAELLA, 2004. p. 19). Esse leitor já tem desenvolvidas diferentes competências para conseguir navegar no ciberespaço e não se perder em seus labirintos e destaca que esse novo tipo de cognição é o que permite ao leitor transitar por esse novo caminho "passando dos objetos aos signos, da imagem ao verbo, do som para a imagem com familiaridade imperceptível" (SANTAELLA, 2004, p. 31). Ao mesmo tempo, a autora alerta que suas "mudanças cognitivas emergentes estão anunciando um novo tipo de sensibilidade perceptiva sinestésica e uma dinâmica mental distribuída que essas mudanças já colocaram em curso e que deverão sedimentar-se cada vez mais no futuro" (SANTAELLA, 2004, p. 184). O número de informações que se recebe e o estímulo à aceleração do pensamento é um fato que leva a modificações "não apenas mentais, mas também corporais e moleculares" (SANTAELLA, 2003a, p. 31).

Nesse contexto, se nos voltamos para os ideais da educação integral confessional, percebemos que esse impacto tecnológico beira ao escândalo! Afinal, será que é possível fazer uso da educação a distância como um meio para estimular processos avançados de reflexão e análise, premissas básicas da filosofia de educação confessional? Apesar de muitos acharem que a resposta seja óbvia, a realidade nos 
instiga à pesquisa e White (2015, p. 186) encoraja: "Pais e professores devem constantemente procurar métodos aperfeiçoados. O ensino da Bíblia deve ter os nossos mais espontâneos pensamentos, nossos melhores métodos, e o nosso mais fervoroso esforço."

Sem dúvida, essa realidade educacional colocou a rede confessional em um momento de análise e reflexão, já que seu objetivo educacional é a educação integral e não apenas passar informação ou instrumentalizar seu aluno. Ou seja, a Rede Adventista enfrenta agora o desafio de integrar a educação a distância aos seus propósitos máximos de educação confessional.

Como docente de tempo integral dessa rede de ensino confessional, que busca 0 desenvolvimento de valores bíblico-cristãos em seus alunos e que acaba de lançar sua primeira licenciatura a distância, sinto que o assunto se faz altamente pertinente. A busca por aliar as possibilidades da tecnologia à filosofia confessional de educação visa a auxiliar o aluno a não só produzir conhecimento, mas fortalecer seu caráter, autonomia e identidade. White (2000) salienta a importância de oferecer um estudo tal ao aluno que ele desenvolva o raciocínio crítico e uma compreensão mais elevada do mundo ao seu redor. Dentro desse contexto de educação, a filosofia de educação confessional entra no cenário com o desafio de reafirmar seus diferenciais de educação cristã e assegurar seu padrão distinto de qualidade em educação integral. Tal cosmovisão possibilita a constatação de pontos distintivos e diferenciais na base de sua engrenagem educacional e altera todo o caminho educacional, influenciando projetos pedagógicos, atividades acadêmicas, métodos de ensino e, por consequência, os objetivos a serem alcançados como resultado da educação. Por certo, é de identidade enraizada em suas bases filosóficas que a educação adventista necessita, mas o que isso significa em um contexto de educação a distância? No contexto confessional, a resposta a essa pergunta traça uma rota de construção social poderosa para determinar e definir os rumos de uma geração.

As bases da educação adventista remontam à bíblia e sua origem, mais especificamente, deu-se na metade final do século XIX, nos Estados Unidos, mesma época em que a filosofia de educação industrial, com promessas de progressos industriais e tecnológicos, ganhava força no Ocidente. Em meio ao espírito dessa época, sentiu-se a necessidade de reformas educacionais e esse clima também inspirou um grupo de fiéis a fundar uma escola diferente. White (2008, p. 398 e 399), educadora e mentora dessa filosofia de educação confessional, explica:

A verdadeira educação inclui todo o ser. Ela ensina o devido emprego do próprio eu. 
Habilita-nos a fazer o melhor uso do cérebro, ossos e músculos; do corpo, mente e coração. As faculdades do espírito são as mais elevadas potências; têm de governar o reino do corpo. Os apetites e paixões naturais devem ser sujeitos ao domínio da consciência e das afeições espirituais.

Como sintetiza Darius e Pancotte (2012, p. 119): "Eis a educação holística de Ellen G. White: competência espiritual, moral, física e intelectual em equilíbrio com Deus e suas criaturas na busca por um mundo melhor aqui e depois". Assim, o intento da educação adventista já era ousadamente distinto do desígnio comum de supervalorização do processo industrial e tecnicista de produção e se voltava para os valores essenciais da vida protegendo seus filhos dos vícios e preparando-os como missionários para servir à sociedade e levar o evangelho ao mundo. Sem neutralidades, o ideal de qualidade na Rede Adventista visa a um propósito pré-estabelecido bem definido: restaurar o homem à imagem de seu Criador. Como coloca White (2008, p. 137):

Mesmo nesta época de paixão pela aquisição do dinheiro, em que a concorrência é grande e os métodos tão pouco escrupulosos, ainda se reconhece amplamente que, para um jovem que se inicia na vida, a integridade, a diligência, a temperança, a pureza e a economia constituem um melhor capital do que qualquer quantidade de simples dinheiro.

No que diz respeito a conceitos e critérios de qualidade da Rede Adventista, Knight (2012), destaca três elementos que revelam a essência da qualidade nesse processo educativo integral: educação como redenção; educação como preparação para todo o período de existência possível ao ser humano e o serviço. Em suma: qual o principal diferencial da educação integral adventista? Knight (2010, p.130) resume: "desenvolver a mente de modo que os cristãos pensem de maneira cristã sobre tudo em suas vidas e sobre cada aspecto de sua existência".

A obra Pedagogia Adventista (2004) discrimina alguns princípios, ou indicadores de qualidade do seu ensino, entre eles: 1) Deus é a Fonte de todo conhecimento, e a verdadeira educação deve fundamentar-se em Jesus Cristo; 2) A bíblia deve constituir a base e o ponto de referência nas atividades educativas na qual as ciências naturais e as Escrituras se complementam mutuamente; 3) Acima das aptidões intelectuais deve estar a formação do caráter; 4) A educação deve ser integral e harmônica, promover a saúde física e mental; 5) A educação cristã exige do professor um perfil adequado; 6) 0 estudante deve ser estimulado a desenvolver seu raciocínio e pensamento próprio; 7) A educação deve preparar para o trabalho. 
Dessa forma, dentro do escopo deste trabalho, partiremos do princípio de que há características específicas no conceito de qualidade para uma educação confessional adventista. Acerca da prática desse conceito de educação integral dentro do ambiente escolar, Holmes (1975, p.8 e 9) afirma:

uma faculdade cristã deveria se preocupar com o desenvolvimento das perspectivas cristãs em todas as áreas da vida e do pensamento. Deveria manter uma Cosmovisão cristã unificadora de forma a entender e participar das várias artes e ciências, bem como de aspectos não-acadêmicos da vida no campus.

Como se vê, além da preocupação com o desenvolvimento dos aspectos sociais, culturais, emocionais e cognitivos, um fator indispensável de qualidade no ensino integral na Rede Adventista é o desenvolvimento da dimensão espiritual, a partir de uma cosmovisão bíblica. Na prática, como resposta de uma educação confessional face aos desafios da filosofia tecnológica e pós-moderna no cenário atual, houve a implementação do Plano Mestre de Desenvolvimento Espiritual (PMDE) no cotidiano de todas as escolas e faculdades da Rede Adventista. Hoje, entre os itens de qualidade da Rede, o PMDE é usado para aplicar os objetivos da área confessional e avaliar se a instituição está servindo de acordo com sua filosofia de educação confessional. Ao instituir esse plano, aplica-se a promulgação da união filosófica e prática dos valores espirituais de forma que a instituição esteja coerente com sua missão e propostas filosóficas.

Becerra (1998) coloca que o PMDE é o documento que aponta temas importantes para serem apresentados a todos os alunos com a finalidade de incentivá-los ao desenvolvimento espiritual e ao crescimento em Cristo. Nesse documento encontramos a promoção de novas experiências de vida, ênfase em propostas para inserção desses valores no dia a dia escolar, a promoção de eventos motivacionais e oferecimento de atividades que procuram desenvolver uma consciência espiritual atingindo os alunos, suas famílias e a comunidade escolar.

\section{A Teoria na Prática}

Nos cursos de Letras do UNASP, tanto na modalidade presencial quanto a distância, a aplicação do PMDE parte dos seguintes princípios:

1. A presença da fé nessa licenciatura vai além da implementação de métodos ou estratégias pontuais. É uma questão de abordagem; 
2. A apresentação do conteúdo do curso parte de uma cosmovisão bíblica de mundo;

3. Há uma integração intencional da fé com atividades apresentadas no curso;

4. São oferecidas oportunidades para serviço voluntário e/ou missionário ao longo do curso.

O ideal é que, ao entrar em contato com a educação adventista, os alunos tenham a oportunidade de sentir, entender e experimentar os princípios da educação adventista ao longo de sua formação. Algumas ações nesse sentido já são tradicionais no curso de Letras presencial, como: a presença de uma pastoral universitária no campus, uma semana de ênfase espiritual por semestre, dias letivos que se abrem com um culto curto e uma oração em cada classe, uma matriz mínima com 2 aulas semanais de religião em classe, e mais a presença de um líder espiritual discente entre os colegas da turma.

A modalidade a distância nos prova que novas estratégias pedagógicas e didáticas nascem de novos contextos e situações educacionais. Sendo assim, no curso de Letras EaD do UNASP, algumas intenções voltadas para a parte confessional ainda estão em construção e aplicação, mas algumas ações já foram colocadas em prática como: 0 conteúdo do material dos ebooks foi validado sob uma perspectiva bíblico-cristã, os alunos cumprem $36 \mathrm{~h}$ semestrais de uma disciplina voltada a temas espirituais, logo na página de entrada do AVA o aluno tem acesso à sala pastoral on-line com oportunidades de participar de estudos da bíblia, devocionais espirituais, um fórum para participação e apresentação dos alunos, oportunidades para participar em projetos de missões e alguns vídeos especiais próprios da área como de apresentação, divulgação dos projetos pastorais, temas voltados para a Semana Santa e para o estudo semanal da bíblia, e já está agendada a primeira semana de ênfase espiritual da licenciatura a distância que será oferecida em junho de 2018.

Na modalidade a distância, não há como abrir um dia letivo com um culto curto e uma oração em cada classe, como feito na modalidade presencial, e ainda não foi aprovada e definida a função e participação de um líder espiritual discente entre os colegas da turma on-line, mas esses são temas em debate e, se adequados e aprovados, serão ajustados à modalidade a distância também. Para avaliar a experimentação dessa prática inovadora e a fim de estabelecer ponderações e reflexões aceitáveis, sem dúvida os critérios da pesquisa científica e do aparato teórico se fazem imprescindíveis. Assim, sugerimos que o fruto deste relato seja um futuro projeto de pesquisa científica qualitativa a fim de dimensionar "o que funciona e o que não funciona" nesse desafio de oferecer educação confessional a distância. 
A fim de descobrir se um curso on-line de uma licenciatura adventista causa impacto na vida espiritual dos alunos, a fase que se segue a esse momento de experimentação em EaD é a da pesquisa científica. Alguns objetivos norteadores de uma futura pesquisa, que poderia ser aplicada ao final do $1^{\circ}$ ano de curso, seriam: Os alunos do curso de Letras EAD acessam a sala da pastoral? Quanto tempo passam ali? Eles leem o devocional on-line? Assistem aos vídeos da sala pastoral? Participam dos grupos de estudo da bíblia? Os alunos são inspirados a se voltar para os temas espirituais da vida ao participarem de um curso de graduação a distância nesta instituição confessional? Como essa cosmovisão é sentida e percebida? Os alunos são motivados a conhecer mais a Cristo?

Avaliar questões relativas à área religiosa se faz possível com indicadores distintos de qualidade e a Rede dispõe de uma filosofia bem fundamentada que possibilita mensurar e analisar o uso da educação a distância como um meio para estimular processos espirituais sensíveis.

\section{Considerações Finais}

Participar na elaboração da primeira licenciatura EaD da Rede Adventista e trabalhar como coordenadora desse primeiro curso de Letras a distância do UNASP tornou-se oportunidade única para levar a cabo a implementação dessa fusão fé e ensino de uma rede confessional de ensino. A partir desta experimentação inovadora, constatamos que a Rede apresenta uma identidade filosófica própria e um diferencial confessional em sua base filosófica de educação. Com o desafio de oferecer um ensino confessional a distância, algumas ações já foram mobilizadas nesse sentido. Certas práticas da modalidade presencial se aplicam e se ajustam à modalidade a distância, mas a modalidade on-line exige algumas adaptações próprias do mundo virtual e permite que a intencionalidade dessa cosmovisão educacional fique visível e que todas as ações da pastoral universitária fiquem disponíveis em uma mesma sala simultaneamente.

A era tecnológica amadureceu um leitor com um novo tipo de cognição pronto para imergir no mundo da educação a distância. Agora, dentro dessa realidade, a Rede Adventista encara mais um desafio: oferecer uma educação confessional a distância de forma que sua filosofia não seja apenas parte do discurso ou de documentos, mas da sua prática educacional concretizando seu objetivo máximo de formação humana.

\section{Referências}

BECERRA, E. Visando Um Plano-Mestre de Desenvolvimento Espiritual. Revista de 
Educação Adventista, v.9, 1998. Disponível em:

http://circle.adventist.org/files/jae/po/jae1998po090303.pdf Acesso em: 20/03/2018

CONFEDERAÇÃO DAS UNIÕES BRASILEIRAS DA IGREJA ADVENTISTA DO SÉTIMO DIA. Pedagogia Adventista. Tatuí: Casa Publicadora Brasileira, 2004.

DARIUS, F. A.; PANCOTTE, R. P. Princípios educacionais em Ellen White. Kerygma. Engenheiro Coelho, volume 8, número 1, 10 sem. de 2012.

FERREIRA, P. V., e SOUZA, R. M. de Q. Educação Adventista: origem, desenvolvimento e expansão. Revista Brasileira de História da Educação, Maringá, PR, v. 18, 2018. Disponível em: http://dx.doi.org/10.4025/rbhe.v18.2018.e001 Acesso em 18 de fev de 2018.

FITZSIMONS, M. Engaging Students' Learning through Active Learning. Irish Journal of Academic Practice: Vol. 3, Iss. 1, Article 13, 2014. Disponível em. Acesso em 24 abril de 2018.

Hybels, S., \& Weaver, II, R. L. Communication effectively. New York: McGraw Hill, 1995.

HOLMES, Arthur F. The Idea of a Christian College. Grand Rapids, Michigan: William B. Eerdmans Publishing company, 1975. Disponível em: goo.gl/FGdusQ. Acesso em 18 de mar de 2018.

KNIGHT, George R. Filosofia e Educação: Uma introdução da perspectiva cristã. Engenheiro Coelho: São Paulo, Imprensa Universitária Adventista, 2012.

Mitos na educação adventista: um estudo interpretativo da educação nos escritos de Ellen G. White. Engenheiro Coelho: UNASPRESS, 2010.

PERRENOUD, P. Dez novas competências para ensinar. Porto Alegre: Artes Médicas Sul, 2000.

SANTAELLA, L. Matrizes da linguagem e pensamento: sonora, visual, verbal. 3. ed. São Paulo: lluminuras, 2009. 
Paulo: Paulus, 2004.

Da cultura das mídias à cibercultura: o advento do pós-humano.

Revista FAMECOS • Porto Alegre • nº $22 \cdot$ dezembro 2003a quadrimestral

- Culturas e artes do pós-humano: da cultura das mídias à cibercultura. São Paulo: Paulus, 2003b.

TARDIF, Maurice. Saberes docentes \& formação profissional. Petrópolis: Vozes, 2002.

WHITE, Ellen G. Educação. Tatuí, SP: Casa Publicadora Brasileira, 2008.

Conselho aos Professores, Pais e Estudantes. Tatuí, SP: Casa Publicadora Brasileira, 2000.

Testemunhos Seletos. Tatuí, SP: Casa Publicadora Brasileira, Vol. 1, 2004

Testemunhos para a Igreja. Tatuí, SP: Casa Publicadora Brasileira,

Vol. 6, 2009. 